\title{
A Portable Impedance Microflow Cytometer for Measuring Cellular Response to Hypoxia
}

\author{
Darryl Dieujuste ${ }^{1}$, Yuhao Qiang ${ }^{1}$, and Sarah Du ${ }^{1}$ \\ ${ }^{1}$ Florida Atlantic University
}

February 28, 2021

\begin{abstract}
This paper presents the development and testing of a low-cost $(<\$ 60)$, portable, electrical impedance based microflow cytometer for single cell analysis under controlled oxygen microenvironment. The system is based on an AD5933 impedance analyzer chip, a microfluidic chip, and an Arduino microcontroller operated by a custom Android application. A representative case study on human red blood cells (RBCs) affected by sickle cell disease is conducted to demonstrate the capability of the cytometry system. An equivalent circuit model of a suspended biological cell is used to interpret the electrical impedance of single flowing RBCs. RBCs exhibit decreased mean membrane capacitance by $24 \%$ upon hypoxia treatment while the mean cytoplasmic resistance remains consistent. RBCs affected by sickle cell disease exhibit decreased cytoplasmic resistance and increased membrane capacitance upon hypoxia treatment. Strong correlations are identified between the changes in the cells' subcellular electrical components and the hypoxia-induced cell sickling process. The results reported in this paper suggest that the developed method of testing demonstrates the potential application for low-cost screening technique for sickle cell disease and other diseases in the field and low-resource settings. The developed system and methodology can be extended to analyze cellular response to hypoxia in other cell types.
\end{abstract}

\section{Hosted file}

Portable flow cytometry_text.pdf available at https://authorea.com/users/398660/articles/ 511297-a-portable-impedance-microflow-cytometer-for-measuring-cellular-response-tohypoxia

\section{Hosted file}

Figures.pdf available at https://authorea.com/users/398660/articles/511297-a-portableimpedance-microflow-cytometer-for-measuring-cellular-response-to-hypoxia 